\title{
Modeling livestock population structure: a geospatial database for Ontario swine farms
}

\author{
Salah Uddin Khan ${ }^{{ }^{*}}$ (D), Terri L. O'Sullivan' ${ }^{1}$ Zvonimir Poljak', Janet Alsop² and Amy L. Greer ${ }^{1 *}$
}

\begin{abstract}
Background: Infectious diseases in farmed animals have economic, social, and health consequences. Foreign animal diseases (FAD) of swine are of significant concern. Mathematical and simulation models are often used to simulate FAD outbreaks and best practices for control. However, simulation outcomes are sensitive to the population structure used. Within Canada, access to individual swine farm population data with which to parameterize models is a challenge because of privacy concerns. Our objective was to develop a methodology to model the farmed swine population in Ontario, Canada that could represent the existing population structure and improve the efficacy of simulation models.

Results: We developed a swine population model based on the factors such as facilities supporting farm infrastructure, land availability, zoning and local regulations, and natural geographic barriers that could affect swine farming in Ontario. Assigned farm locations were equal to the swine farm density described in the 2011 Canadian Census of Agriculture. Farms were then randomly assigned to farm types proportional to the existing swine herd types. We compared the swine population models with a known database of swine farm locations in Ontario and found that the modeled population was representative of farm locations with a high accuracy (AUC: 0.91, Standard deviation: 0.02) suggesting that our algorithm generated a reasonable approximation of farm locations in Ontario.

Conclusion: In the absence of a readily accessible dataset providing details of the relative locations of swine farms in Ontario, development of a model livestock population that captures key characteristics of the true population structure while protecting privacy concerns is an important methodological advancement. This methodology will be useful for individuals interested in modeling the spread of pathogens between farms across a landscape and using these models to evaluate disease control strategies.
\end{abstract}

Keywords: Synthetic population, Swine, Pigs, Farms, Ontario, Infectious disease transmission model

\section{Background}

The Canadian swine industry has gone through a major transformation in the last century. The number of pig farms has decreased from 8.1 in 1921 to 0.6 per 100 inhabitants in 2011 [1], but the average number of pigs raised per farm has continued to grow in Canada. In 2011, the swine industry was the fourth largest agricultural industry (CAD 3.9 billion value) in Canada after canola, dairy products and beef cattle [1]. During the same year, Canada exported more than one million tons of pork valued at $\$ 2.9$ billion to more than 80 countries and was ranked as the fifth largest pork exporter in the

\footnotetext{
*Correspondence: sukhanbd@uoguelph.ca; agreer@uoguelph.ca ${ }^{1}$ Department of Population Medicine, Ontario Veterinary College, University of Guelph, Guelph, ON, Canada

Full list of author information is available at the end of the article
}

world [2]. Ontario is considered to be the second largest swine producing province in Canada with $24.4 \%$ of all pigs and the majority are in southern Ontario [3]. It is hypothesized that areas with a high density of farms are at greater risk for infectious disease introduction and spread $[4,5]$.

Infectious diseases in farmed animals have economic, social, and animal health consequences as well a possible human health consequences [6]. Foreign animal diseases (FAD) of swine are of significant concern in terms of animal health and welfare and also due to the anticipated economic losses that would arise as a result of a FAD incursion in Ontario [2]. Because FAD introductions are rare events especially in more developed countries with rigorous importation regulations on animals and animal products, mathematical and epidemiological 
modeling are often used to simulate the extent of such outbreaks and best practices for control using what are considered to be the "most likely" scenarios [7].

Disease modeling provides a cost-effective approach for researchers to develop an understanding of the determinants of disease spread within a population and factors contributing to effective disease control [8]. Host-pathogen relationships frequently demonstrate non-linear trends. Such complex relationships are often best described by computer simulation models [8]. This methodology has contributed to our understanding of disease dynamics and how best to intervene in order to prevent the spread of an infectious disease $[8,9]$. However, simulation outcomes are sensitive to the geographic location of livestock enterprises, the number of animals present at each location, and the frequency of both direct and indirect movement events between livestock enterprise locations [10, 11]. In Canada, access to individual swine farm population data with which to parameterize models is limited because of privacy concerns. Authorities responsible for disease outbreak response such as Canadian Food Inspection Agency (CFIA) and Ontario Ministry of Agriculture, Food and Rural Affairs (OMAFRA) do not maintain a livestock population database of animals susceptible to FAD or other reportable diseases. Rather, they rely on premise and animal identification databases maintained by the provincial or territorial governments and/or by livestock traceability administrators, such as Pig Trace Canada (Personal communication: Pascale Aubry, CFIA and Tim Pasma, OMAFRA). Although CFIA and OMAFRA have a data sharing agreement in the event of an outbreak, access to the livestock location database is restricted to use during an animal disease emergency. Therefore, our objective was to develop a methodology to model farmed swine population in Ontario, Canada that captured the most important aspects of the existing swine farm population structure in Ontario in order to improve the realism of computer simulation models.

\section{Methods}

Swine farming in Ontario and 2011 census database structure

Statistics Canada conducts an agricultural census once every five years and detailed data for the most recent agricultural census (2011) was publicly available from the Statistics Canada website [3]. The Canadian census data on swine farming consisted of the number and types of farms, and the aggregated number of animals (Additional file 1: Table S1, Figure S1, S2). The smallest unit of the aggregated farming data was Census Consolidated Subdivisions (CCS). Formation of a CCS depended on multiple factors that included a census subdivision consisting of a land area greater than $25 \mathrm{~km}^{2}$ or having a human population size greater than 100,000 [12].
Swine farm data were extracted from the 2011 Agricultural Census by CCS, the smallest aggregated geographical unit. However, there were two limitations related to the spatial resolution of the data available for analysis. First, a large proportion of data on the total number of animals in a farm were missing. Based on production type, the missing data ranged from $33 \%$ to $48 \%$ (Additional file 1: Table S1). And second, the format of the census data did not distinguish mixed farm types (e.g. farms having multiple swine production types), which is a feature of the swine population commonly observed in Southern Ontario [13]. These limitations made the dataset less useful for assessing the overall number of pigs and types of swine farms in each CCS. Therefore, we only utilized the total number of pig farms as reported in the 2011 census for our model. We performed additional data processing to match geographic boundary files of Ontario CCS with the 2011 Census swine population data to develop a geospatial database that matched the swine farm density reported in the 2011 Census data (Additional file 1: Figure S1, S2).

\section{Data processing and evaluation}

We have described the estimation and validation of the spatial locations of swine farms in Ontario, Canada as a six-step process: This included 1) identifying ecological and anthropogenic factors that may affect swine farming; 2) defining the relative importance of the factors affecting swine farming, 3) generating an algorithm to achieve a likelihood score for swine farming in a particular location; 4) estimating the suitability of a location for swine farming; 5) generating random farm locations equal to the swine farm density reported in the 2011 Census of Agriculture, and 6) validate the methods for estimating swine farming likelihood.

\section{Understanding the factors influencing the locations of swine farms in Ontario}

We consulted with swine experts in Ontario (Drs. Zvonimir Poljak and Terri L. O'Sullivan, Ontario Veterinary College, University of Guelph, and Dr. Tim Pasma, Lead Veterinarian and Epidemiologist, Animal Health and Welfare Branch of the Ontario Ministry of Agriculture, Food and Rural Affairs, Guelph, Ontario, Canada) through multiple face-to-face meetings, and email communications, reviewed available farm data, and performed literature searches to determine the factors influencing swine farming in Ontario (Table 1) $[14,15]$. Like any other commercial operation, we assumed that access to transportation was one of the key drivers for the establishment of a swine farm. Additionally, we assumed that the local regulations for agricultural land use, land availability and facilities supporting farm infrastructure also played key roles in determining suitable swine farm locations $[14,15]$. Key drivers for zoning regulations by the local and provincial authorities included 
Table 1 Factors influencing the locations of swine farms in Ontario, scoring guidelines, and geographic information system data used to assign scores

\begin{tabular}{|c|c|c|}
\hline Attributes & Scoring guideline & GIS Data \\
\hline \multicolumn{3}{|l|}{ Zoning and Local Regulations } \\
\hline Population centers & $\begin{array}{l}\text { Farms are not allowed to be established within a municipality } \\
\text { or a population center }\end{array}$ & $\begin{array}{l}\text { Ontario Population Centers /Residential } \\
\text { Land Use }\end{array}$ \\
\hline Agricultural zone & $\begin{array}{l}\text { Swine farms are encouraged to be established within the area } \\
\text { zoned for agricultural use }\end{array}$ & Agricultural ecumene \\
\hline Roads within population center & $\begin{array}{l}\text { Although farms are almost always near a road network, the } \\
\text { roads passing within a population center or residential area } \\
\text { should be away from a swine farm }\end{array}$ & $\begin{array}{l}\text { Road Network Passing through } \\
\text { a population Center/ Residential } \\
\text { Location }\end{array}$ \\
\hline \multicolumn{3}{|l|}{ Land Availability } \\
\hline Crown Land & $\begin{array}{l}\text { Crown Land - MNR Unpatented Land Public are not supposed } \\
\text { to have any private establishment. However, since the most } \\
\text { recent update in the database (2010), a proportion of the land } \\
\text { may have been given access to public. Therefore, we assigned } \\
\text { a suitability score of } 5 \% \text { within the Crown Land, and } 100 \% \text { for } \\
\text { the remainder }\end{array}$ & $\begin{array}{l}\text { Crown Land - MNR Unpatented } \\
\text { Land Public }\end{array}$ \\
\hline Crown Game Preserves & $\begin{array}{l}\text { Farms are not allowed to be established on land designated for } \\
\text { Crown game preserves }\end{array}$ & Crown Game Preserves \\
\hline Government Institutional Land Use & $\begin{array}{l}\text { Farms are not allowed to be established on land designated } \\
\text { for government institutions }\end{array}$ & Government Institutional Land Use \\
\hline Industrial Land Use & $\begin{array}{l}\text { Farms are not generally allowed to be established on land } \\
\text { designated for industrial establishments }\end{array}$ & Resources and Industrial Land Use \\
\hline Camp, Recreation & $\begin{array}{l}\text { Farms should be located a certain distance from camp and } \\
\text { recreational establishments }\end{array}$ & Camp, Recreation \\
\hline \multicolumn{3}{|l|}{ Facilities Supporting Farm Infrastructure } \\
\hline \multirow[t]{2}{*}{ Road Network } & $\begin{array}{l}\text { Roads that do not got through population centers have a } \\
\text { higher likelihood of being near swine farms }\end{array}$ & Road Network \\
\hline & $\begin{array}{l}\text { Swine farms could be located near highways, but their access } \\
\text { to transportation will depend on the local road network } \\
\text { connecting the farms, thus we only kept the local road } \\
\text { network attribute. }\end{array}$ & \\
\hline \multicolumn{3}{|l|}{ Geographic Barriers } \\
\hline Waterbodies & $\begin{array}{l}\text { Swine farms are generally not located near shorelines of } \\
\text { the large waterbodies (e.g. Great Lakes). Therefore, we } \\
\text { considered that it would be unlikely that farms would be } \\
\text { within } 1 \mathrm{~km} \text { of the shorelines of the Great Lakes. }\end{array}$ & Great Lakes \\
\hline Large Inland Waterbodies & $\begin{array}{l}\text { We consider it highly unlikely that a swine farm would be } \\
\text { located within the boundaries of large inland waterbodies } \\
\text { (e.g. rivers and lakes). }\end{array}$ & Inland lakes and rivers \\
\hline
\end{tabular}

concerns related to water and air pollution and odour control [15]. Production waste (i.e. manure) resulting from intense swine farming was identified as a key environmental concern [15]. Because swine farm waste materials contain a high concentrations of nitrate, phosphate, salts, and bacteria, they may pollute nearby open water sources [15], triggering risks for the health of human, animal, and aquatic ecosystems. As a result, many of the regulations and guidelines focus on containing swine farms within specific agricultural zones in order to have sufficient space to store, handle, and process farm waste materials. Since southern Ontario mostly consists of gently rolling plains, larger waterbodies were the only noticeable natural barriers for the establishment of swine farms [16]. However, because of the current regulations for environmental safety, we assumed that swine farms needed to be situated a reasonable distance from large open waterbodies to prevent contaminants from farm waste materials. Other factors, such as the land designated for population and urban centers, government institutional uses, industrial zones, Crown game preserves, camps and recreational uses, and Crown lands added additional restrictions for areas that could support swine farming in Ontario (Table 1).

\section{Developing geospatial data layers and assigning suitability scores}

To assess the factors influencing swine farming in Ontario (Additional file 1: Figure S3), we identified the geospatial 
databases that could capture zoning and local regulations, farm land availability, facilities supporting farm infrastructure, and geographic barriers (Table 2). Multiple data processing steps were necessary to assign and combine the suitability scores into a single geospatial dataset. We reprojected all of our geographical data layers to The Lambert Conformal Conic map projection, a map projection system frequently used in Ontario [17].

We divided the province of Ontario into $1 \mathrm{~km}^{2}$ geospatial grids as data units and calculated the distance between each unit and the nearest factors influencing swine farming (Table 2). The next step included assigning suitability scores based on the distance between the outer boundary of a geospatial grid and a factor influencing swine farming (Table 2). For example, the likelihood of a farm being within $300 \mathrm{~m}$ of a road that does not intersect a residential location is very high because of the ease of transporting animals and goods. However, as a farm location unit moves further away from road networks, transportation logistics become more difficult. With a conservative approach, we assumed that it would not be logistically feasible to establish a farm five kilometers away from the nearest road network. Similarly, because of the local regulations [15], pig farms could not be established within a population center or residential zone, thus we assigned a likelihood score of zero to these area of the geospatial grid. Initially, we assumed that pig farms would need to maintain a sufficient distance from provincial population centers. However, when we assessed publicly available pig farm location data from Ontario $(n=45$, data not shown), there were a small proportion of farms within the two kilometer buffer outside the population centers. Therefore, we assigned a lower likelihood score to the geospatial units within the two kilometer buffer outside the population centers than the geospatial units more than two

Table 2 Geospatial data layers and the associated suitability scores for the prospect of having a swine farm in a particular geographical location

\begin{tabular}{|c|c|c|c|}
\hline GIS data layers & Data source & Categories & Suitability scores \\
\hline \multirow{6}{*}{$\begin{array}{l}\text { Road Network } \\
\text { (excluding highways) }\end{array}$} & \multirow[t]{6}{*}{ StatCan } & Roads passing through population centers & 0 \\
\hline & & Roads that don't pass through population centers. & \\
\hline & & - Within 300 m & 100 \\
\hline & & - Between 301 and 500 m & 50 \\
\hline & & - Between 501 and $5000 \mathrm{~m}$ & 25 \\
\hline & & - More than 5 KM & 0 \\
\hline \multirow[t]{2}{*}{ Agricultural Ecumene ${ }^{a}$} & \multirow[t]{2}{*}{ StatCan } & - Intersect & 100 \\
\hline & & - Do not intersect & 10 \\
\hline \multirow{4}{*}{$\begin{array}{l}\text { Population Centers/ } \\
\text { Residential Zones }\end{array}$} & \multirow[t]{4}{*}{ StatCan and DMTI Spatial Inc. } & - Within a population center/residential zone & 0 \\
\hline & & $\begin{array}{l}\text { - Within a } 2 \mathrm{KM} \text { buffer around the outer perimeter of } \\
\text { a population center }\end{array}$ & 25 \\
\hline & & - Between 2.001 and 15 KM buffer around a population center & 95 \\
\hline & & $\begin{array}{l}\text { - More than } 15 \mathrm{KM} \text { away from the outer perimeter of a } \\
\text { population center }\end{array}$ & 50 \\
\hline \multirow{2}{*}{$\begin{array}{l}\text { Crown Land - MNR } \\
\text { Unpatented Land Public }\end{array}$} & \multirow{2}{*}{$\begin{array}{l}\text { Ontario Land use information, } \\
\text { Ministry of Natural resources }\end{array}$} & - Intersect & 5 \\
\hline & & - Do not intersect & 100 \\
\hline \multirow[t]{2}{*}{ Camp and Recreation spots } & \multirow{2}{*}{$\begin{array}{l}\text { Ontario Land use information, } \\
\text { Ministry of Natural resources }\end{array}$} & - Intersect within $1 \mathrm{KM}$ buffer of the outer perimeter & 0 \\
\hline & & - Outside $1 \mathrm{KM}$ buffer of the outer perimeter & 100 \\
\hline \multirow{2}{*}{$\begin{array}{l}\text { Government Institutional } \\
\text { Land Use }\end{array}$} & \multirow[t]{2}{*}{ DMTI Spatial Inc. } & - Intersect & 0 \\
\hline & & - Do not intersect & 100 \\
\hline \multirow{2}{*}{$\begin{array}{l}\text { Resource and Industrial } \\
\text { Land Use }\end{array}$} & \multirow[t]{2}{*}{ DMTI Spatial Inc. } & - Intersect & 0 \\
\hline & & - Do not intersect & 100 \\
\hline \multirow[t]{2}{*}{ Waterbodies - Great Lakes } & \multirow[t]{2}{*}{ NOAA } & - Intersect within $1 \mathrm{KM}$ buffer of the outer perimeter & 0 \\
\hline & & - Outside $1 \mathrm{KM}$ buffer of the outer perimeter & 100 \\
\hline \multirow[t]{3}{*}{ Large Inland Waterbodies } & \multirow[t]{3}{*}{ StatCan } & $\begin{array}{l}\text { Larger waterbodies (e.g. ranking 1, } 2 \text { and 3). A geographical } \\
\text { reference location: }\end{array}$ & \\
\hline & & - Intersect within $1 \mathrm{KM}$ buffer of the outer perimeter & 0 \\
\hline & & - Outside 1KM buffer of the outer perimeter & 100 \\
\hline
\end{tabular}

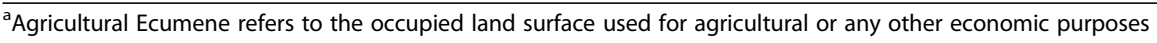


kilometers outside the population centers. We also assumed that the likelihood of a farm being more than $15 \mathrm{~km}$ away from the nearest population center is lower because of the logistics and costs associated with animal, animal product, and farm supplies and consumables transportation. Agricultural zones were of specific focus for assigning probability scores because the majority of the surface within the zone consisted of the loam soil types. This particular soil type supports the storage and draining of organic waste materials produced on a farm [14] and for this reason we assigned a high likelihood score for geospatial units within a defined agricultural zone. Because of the current local regulations relating to open water pollution, farms should maintain sufficient distance from open-water sources. Hence, we created a $1-\mathrm{km}$ buffer around the larger waterbodies and calculated the distance between a geospatial unit and the nearest water source. The geospatial units that intersected a water body, received a likelihood score of zero. However, assigning probability scores to the geospatial units near waterbodies presented a challenge because a single geospatial unit may intersect with the $1 \mathrm{~km}$ buffer zone, but a large proportion of the surface of the unit might have sufficient space to accommodate a farm (Additional file 1: Figure S4). For this reason, we subtracted the land surface covered by the polygons generated from the ' $1-\mathrm{km}$ buffer to the waterbodies' from the dataset. Performing this action allowed us to retain portions of a geospatial unit with space that could accommodate a swine farm.

\section{Combined suitability score for pig farming operations and random farm placement}

To develop a combined pig farm suitability surface, we developed an algorithm consistent with the suitability scores calculated for each of the individual level factors that were identified as influencing pig farming in Ontario. Figure 1 is an example of calculating a combined suitability surface: step 1 consisted of the process of multiplying the input parameters with scores assigned for each of the geospatial units and step 2 consisted of regressing the combined suitability scores to a scale ranging from zero to one. With zero being completely unsuitable and one being completely suitable based on the defined algorithm.

Once we calculated the combined pig farm placement suitability scores, we generated random farm locations within the geospatial units that exceeded a defined threshold (methods described in the model accuracy assessment section). The random points generated within a CCS were equal to the number of farms reported in the 2011 agricultural census [18]. Additionally, random points were not permitted within $300 \mathrm{~m}$ of each other. The minimum distance of $300 \mathrm{~m}$ were selected based on the observed distance characteristics of the publicly available pig farm data in Ontario (data not shown).

\section{Validate the methods for estimating swine farming likelihood}

To assess the accuracy of the models, we followed standard approaches to generate agreement matrices [19-21] in order to compare the level of agreement between the predicted combined suitability score of the models and the "reference" presence or absence data. The presence/ absence pig farm data for a geographical unit served as a reference dataset for evaluating the classification accuracy of the predictive models.

The reference data on pig farm premises for validation of the model-generated swine population was derived from the Ontario Provincial Premises Registry collected by the Ontario Ministry of Agriculture, Food, and Rural Affairs [22]. The Provincial Premises Registry provides a premises identification number for those who voluntarily registered their agri-food businesses, which includes livestock farms. Although premises registration was voluntary, the compliance rate was very close to $100 \%$ because the farms were required to have a premises identification number to report pig movements to meet federal reporting regulation (Personal communication, Ontario Ministry of Agriculture, Food, and Rural Affairs). Most importantly, for the purpose of validating the modeled swine population

$\underline{\text { Step } 1}$

\begin{tabular}{|c|c|c|c|c|c|c|c|c|c|c|c|c|c|c|}
\hline \multicolumn{3}{|c|}{ Road Network } & \multirow{3}{*}{$x$} & \multicolumn{3}{|c|}{ Population Centers } & \multirow{3}{*}{$x$} & \multicolumn{3}{|c|}{ Crown Land } & \multirow{3}{*}{$=$} & \multicolumn{3}{|c|}{ Combined Score } \\
\hline 0 & 100 & 75 & & 0 & 50 & 95 & & 100 & 100 & 100 & & 0 & 500000 & 712500 \\
\hline 5 & 50 & 50 & & 50 & 95 & 30 & & 100 & 100 & 5 & & 25000 & 475000 & 7500 \\
\hline
\end{tabular}

$\underline{\text { Step } 2}$

\begin{tabular}{|c|c|c|}
\hline \multicolumn{3}{|c|}{ Combined Score } \\
\hline 0 & 500000 & 712500 \\
\hline 25000 & 475000 & 7500 \\
\hline
\end{tabular}$\quad 100^{3}=$\begin{tabular}{|c|c|c|}
\hline \multicolumn{3}{|c|}{ Combined Suitability Surface } \\
\hline 0.00 & 0.50 & 0.71 \\
\hline 0.03 & 0.48 & 0.01 \\
\hline
\end{tabular}

Fig. 1 An example of calculating a combined suitability surface: step 1 of the process required multiplying the input parameters with the scores assigned for each of the geospatial units, and step 2, consisted of regressing the combined suitability scores to a scale ranging from 0 to 1 
algorithm, premise registration records included information regarding the geographic location of the centroid of a parcel of land where the farm is located or individual barns of the swine farms. The total number of registered premises within the province of Ontario was approximately double the number of farms listed in the 2011 agricultural census likely because many of the farms registered multiple premises or there was an underreporting of swine farms in the 2011 census or both.

To assess model validity, we compared the algorithmgenerated swine farm locations for the modeled swine datasets that received no score (i.e. zero, not suitable for pig farm) with those that received a positive score (i.e. non-zero, could support a pig farm) to the geographical location units that had presence or absence information on pig farm operations from the Provincial Premises Registry. The Provincial Premises Registry served as the reference dataset for model validation.

We developed multiple models by varying the combinations of explanatory variables. To begin with, we identified a minimal required set of explanatory variables that could explain probable pig farming locations and assess the accuracy. Considering the logistical challenges with assigning suitability scores to the surfaces intersecting with waterbodies (Additional file 1: Figure S4) and the probability that farms could have been placed near waterbodies before regulations were in place (e.g. previously described publicly available swine farm location data identified $4.4 \%$ of the farms were within one kilometer near a waterbody), we removed the variables explaining different types of waterbodies (from small to large) from models 2 through 5 to assess the changes in model accuracy (Table 3). We initially assumed that the explanatory variables included in model 1 were sufficient to assign a probability score for swine farm locations. However, since the Crown land database (Crown Land - MNR Unpatented Land) was somewhat dated (last update in 2010), we included this variable in model 4 to assess the difference in model accuracy. We also hypothesized that the explanatory variables in model 1 would be sufficient to represent agricultural zones because they excluded the population centers and other non-agricultural related land uses. To explore this, we included the agricultural ecumene to model 6 to assess the changes in model efficacy.

Since we developed multiple models based on a range of different assumptions, we followed a two-step approach for model selection and assessment of validity. First, for each of the population models (Table 3), we calculated the area under the receiver operating characteristic (ROC) curve using the Mann-Whitney U statistic [23]. The hypothesis was that that a randomly chosen 1$\mathrm{km}^{2}$ surface with a pig farm present (from the Provincial Premises Registry) would receive a higher likelihood score compared to the randomly chosen geographical unit without any pig farms. In the second step, True Skill Statistics (measured as: sensitivity + specificity - 1) [24] and Kappa values were calculated to identify an optimal threshold cut-off for the model's combined suitability score that demonstrated maximum sensitivity and specificity $[21,25]$.

Once we identified an optimal threshold for the model with the highest area under the ROC curve (AUC), we generated random spatial points from a uniform distribution [18] to represent farm locations for the population model within the geographical surface that scored equal to or above the threshold likelihood score. The

Table 3 Accuracy statistics of the model swine populations: area under the receiver operating characteristics curve (AUC) and standard deviations (Sd)

\begin{tabular}{l}
\hline Models \\
\hline Model1 \\
Road network + population centers and residential zones + camp and recreational \\
spots + government institutional land use + resources and industrial land use + great \\
lakes + large inland waterbodies + small inland waterbodies \\
Model2 \\
Removed small inland waterbodies from Model1 \\
Model3 \\
Removed large inland waterbodies with 1 KM buffer from Model2 surface \\
Model4 \\
Included Crown Land - MNR Unpatented public land to Model3 \\
Model5 \\
Removed great lakes with 1 KM buffer from Model4 surface \\
Model6 \\
Included agricultural ecumene to Model5
\end{tabular}

${ }^{a}$ Removed was defined as the section(s) of a surface unit intersecting with a predictor which was not included in the computation 
number of random modeled farm location points within a Census Consolidated Subdivision (CCS) was equal to the number of pig farms described in the 2011 Agricultural Census. Once the farm locations were assigned, we randomly assigned the type of swine operation (e.g. farrow to finish, finisher farm types) proportional to the recently surveyed operation types [13]. The farm types were also randomly assigned a size (number of pigs per farm) based on the farm-level population distribution from the 2011 census information.

\section{Results}

Attributes that received a suitability score to support swine farming had varying degrees of land surface coverage: highest land surface (31\%) was covered by the proximity to the road network and the least $(0.6 \%)$ was by government and institutional land use (Additional file 1: Table S2). Models to generate a combined likelihood scores to identify pig farming locations in Ontario demonstrated relatively high accuracy (Table 3 ). A suitable model (Model 6, Fig. 2) was achieved by incorporating distance information on road networks, population centers and residential zones, camps and recreational centers, land used by government, resources, and industrial purposes, and agricultural zoning and subtracting the landscape areas that had larger waterbodies or were within a $1 \mathrm{~km}$ buffer zone of a larger waterbody. Model
6 demonstrated a very high predictive accuracy (AUC: 0.90, Standard deviation (SD): 0.003) (Fig. 3) when compared to the premises registry information describing pig farming in Ontario (Table 3). The model predicted 9.6\% of the Ontario's land surfaces, mostly in southern Ontario suitable for supporting pig farms. When comparing model algorithms to the true pig farming locations (premises registry), we used the higher threshold cut-off identified between two distinct approaches: True Skill Statistics and Kappa Statistics. A likelihood threshold of 0.82 was identified as an optimal cut-off (Sensitivity: 72\%, Specificity: 96\%) (Figs. 3 and 4). The land surfaces that scored on and above this threshold cut-off were selected to generate random farm locations $(n=2485)$ equal to the number of swine farms documented in the 2011 Canadian agricultural census. When compared to the known pig farming locations (census consolidated subdivisions) described in the 2011 census, the randomly generated farm location points (Fig. 5) demonstrated very high accuracy (AUC: 0.93, SD: 0.01).

\section{Discussion}

We developed a model to generate a swine population to represent the farm population structure for commercially raised pigs in Ontario. Publicly available data from the 2011 Canadian agricultural census and geospatial information were used to generate a swine population

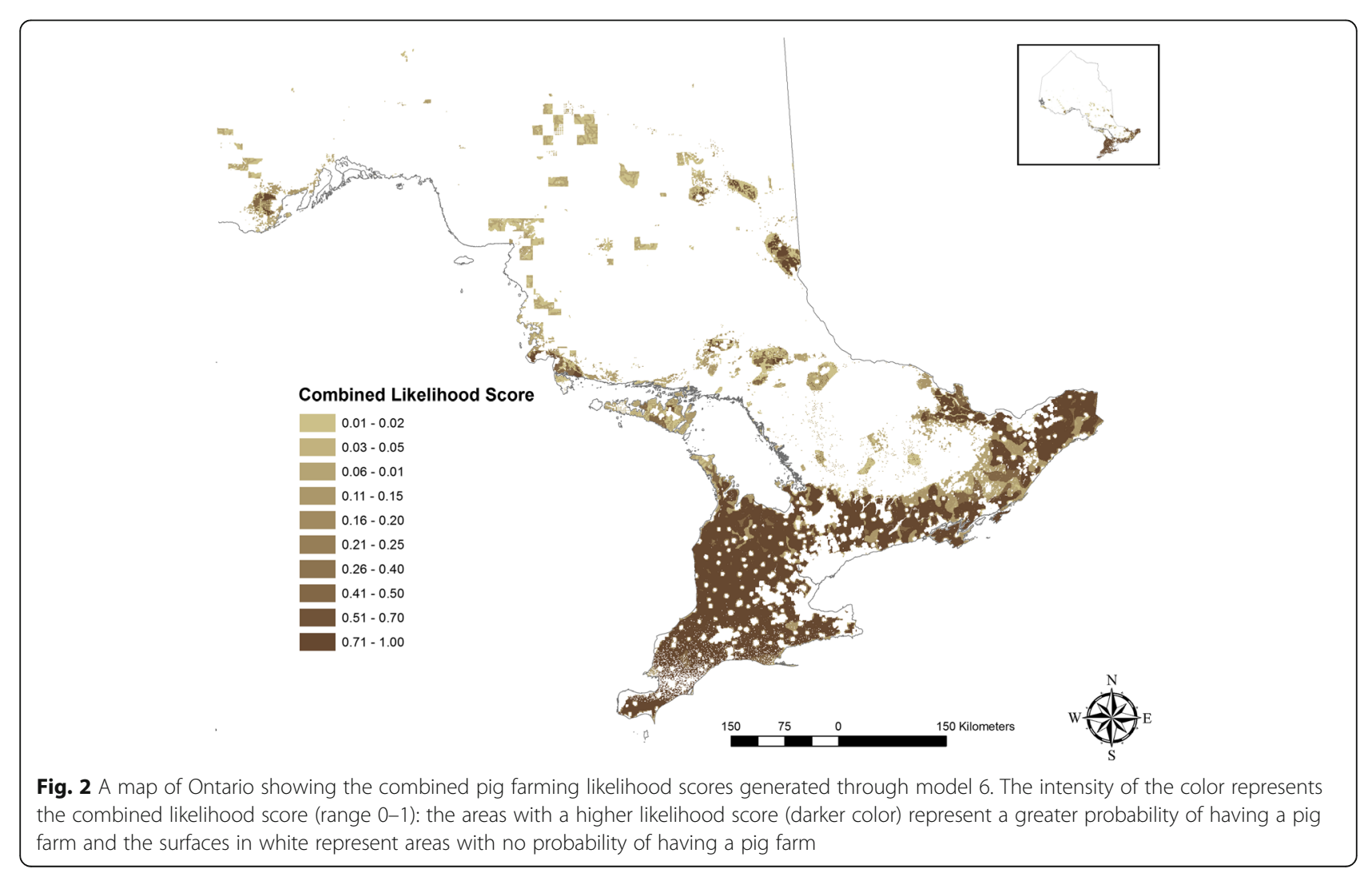




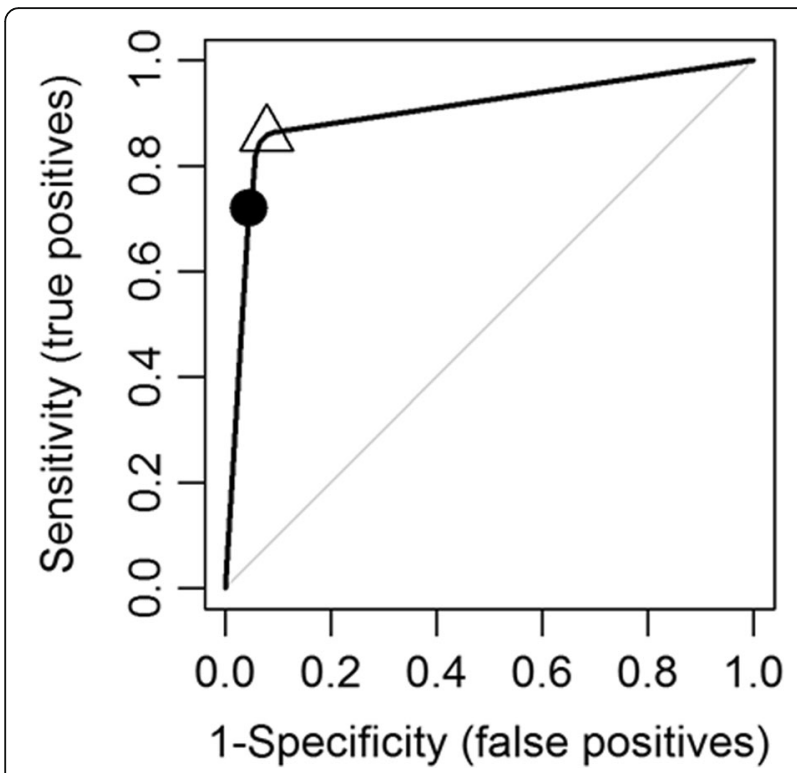

Fig. 3 A receiver operating characteristic $(R O C)$ plot for the combined likelihood score's predictability of model 6, with the optimal threshold marked along the ROC curve. The hollow triangle shape and the black circle indicate the sensitivity and specificity associated with True Skill Statistics (0.04) and the maximum Kappa value (0.82) respectively

structure that represents an improvement over alternative methods, such as the random placement of farm locations across the landscape [26]. When compared with the actual geospatial location information for pig farms in Ontario, the model demonstrated high accuracy.

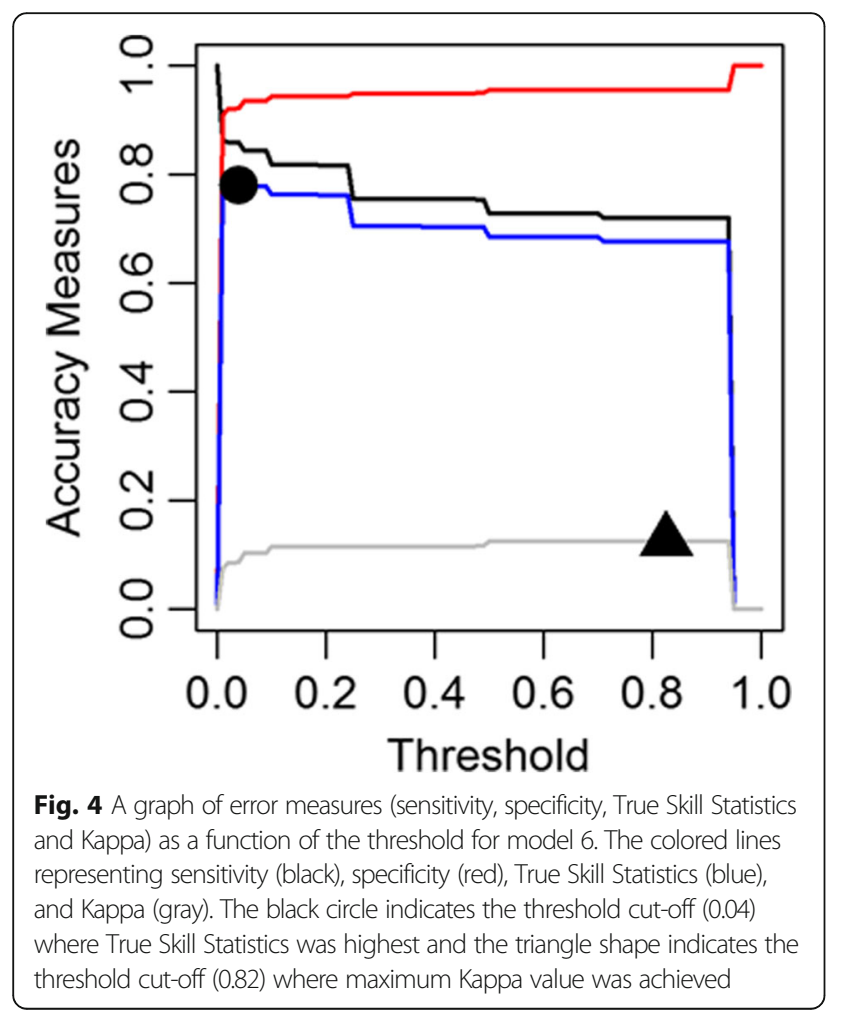

Generating a well validated model population of swine farms means that this model population could be used as an input into disease simulation models. This will enable researchers to examine questions related to the prevention and control of pathogens within the swine industry including FAD, while at the same time protecting the privacy of individual pork producers. This approach could be replicated for other agricultural commodity groups (e.g. poultry, beef cattle etc.) for which limited individual level data exist.

Our approach was to identify a minimum set of predictors required to assign each cell of a regular grid applied across the geographical extent of Ontario a score reflecting the probability that a pig farm would be present. We hypothesized that regional, cultural, regulation, and landscape factors would be major drivers of the establishment of swine farms. We assigned suitability scores based on a combination of expert opinion, literature reviews, and logic. The models developed based on different combinations of predictors have demonstrated moderate to high accuracy (Table 3 ). The combination of predictors to create multiple models further helped to assess the predictor selection procedure, particularly the importance of incorporating 'logic' (step 6) to improve model accuracy. In addition, we matched the production types and number of animals on each farm based on the known distribution from recent surveys [13] and the 2011 census [3] to develop a realistic population structure for the province of Ontario. Our findings provide a methodology to estimate the likely geographic location of swine enterprises in a given area. This approach can be used to simulate a population of farms that provides a reasonable estimate of both the number of farms and the location of farms in a study area. A similar approach has been used to model commercial poultry farm locations in the United States [26]. The modeled poultry population was later used to generate parameter estimates for highly pathogenic avian influenza transmission models [26, 27].

There has been tremendous growth in the Canadian swine industry over the past few decades. However, profits have varied dramatically for several reasons, including the increased input costs (e.g. feed), disease outbreaks, changes in the value of the Canadian dollar, and changes in North American pork prices [28]. FAD outbreaks are particularly important not only because of the direct impact on production, but also because of the destruction of healthy animals due to welfare slaughter, import bans by Canadian trading partners, and the risk of a long-term import ban by some countries [2, 3]. Between 1921 and 2011, agricultural intensification in commercial swine production has decreased the number of Canadian swine farms from 711,090 to 7371 , but in the same time period, the number of pigs raised has increased from 9 


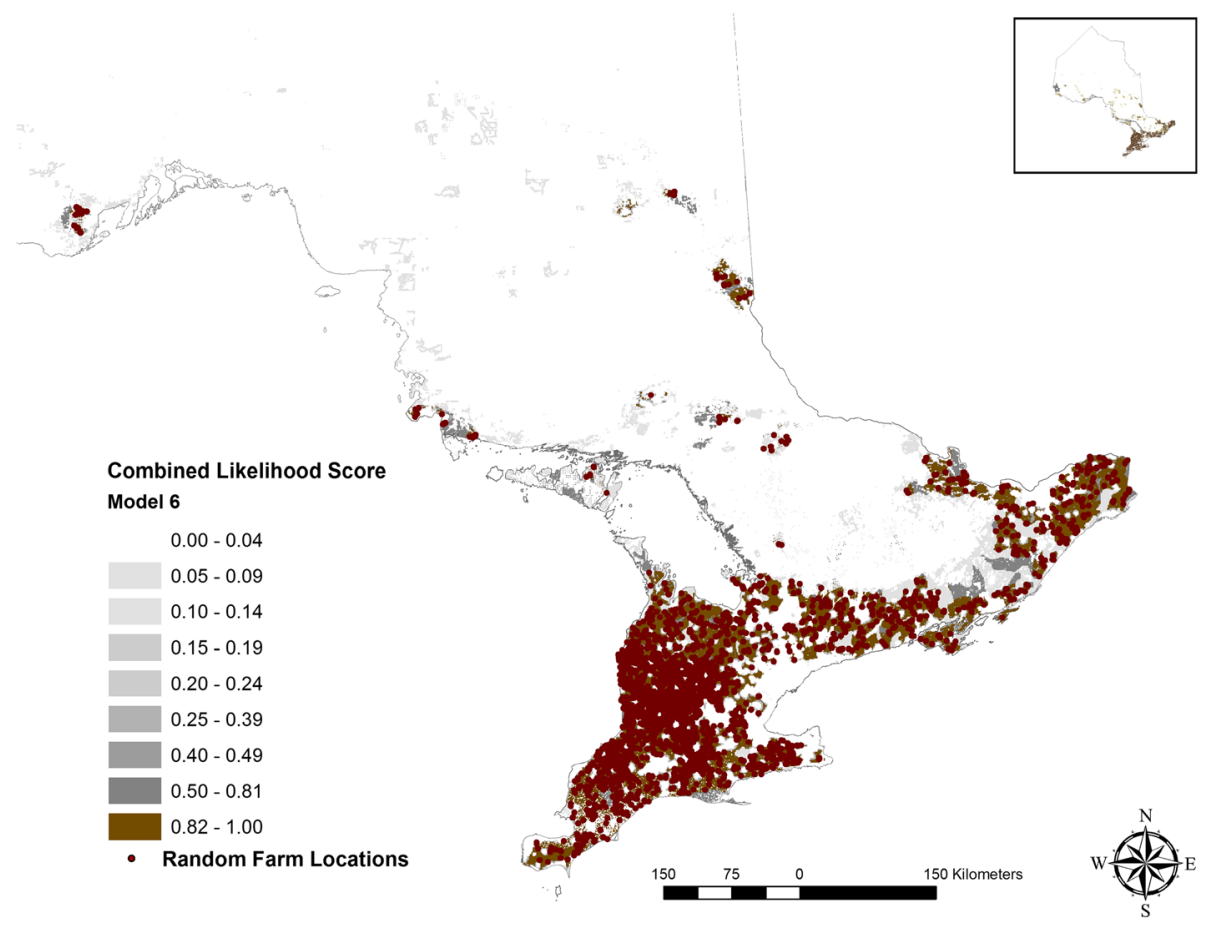

Fig. 5 Random pig farm locations generated using model 6 and based on a combined likelihood threshold cut-off value of 0.82.The red dots $(n=2485)$ represent the locations of model pig farms generated on the surfaces that fall above the likelihood threshold cut-off value. The color intensity on the background represents the combined likelihood threshold

million to 33 million pigs [29]. Although the transformation from backyard swine farms to commercial farming operations increases the likelihood that good biosecurity practices will be carried out, the potential introduction of a FAD remains a major concern for the Canadian swine industry. One recent example was in 2009, when countries such as China and Russia placed a ban on Canadian pork imports because of pandemic influenza A (H1N1). This forced some producers to downsize or exit the industry through government assistance programs $[1,30]$.

The introduction of a FAD into the Canadian swine industry would have an enormous economic impact. In order to mitigate this risk, preparedness planning is required to estimate the possible extent of an FAD outbreak, the expected efficacy of the control and eradication measures that would be applied in the event of an outbreak, and the human resource and infrastructure requirements (e.g. the number of veterinarians, technicians, disposal services etc.) necessary to effectively carry out control and eradication measures. One of the key requirements for preparedness planning requires the development and parameterization of disease transmission models that incorporate accurate farm population structure that would serve as the base for the disease transmission model $[10,11]$. The methodology described here, provides one such example of how this population structure can be derived. The spread of a livestock pathogen is primarily influenced by three factors: first, the variability of disease susceptibility in different production types, second, the geographical proximity and clustering of farms, and third, the direct and indirect movement of animals, people, feed, fomites, vehicles and animal products between different production types [31-34]. Estimating the direct and indirect movements between farms was out of the scope of this research however, to capture the static swine farm characteristics, we developed a spatially explicit population of swine farm locations in Ontario, classified the farms to different production types based on a recent survey [13], and assigned numbers of animals in each farm based on the farm-level population distribution from 2011 agricultural census. The farm locations were randomly generated across the land surface with a likelihood of supporting a swine farm and farm density matched with the census units. The production types and the numbers of animals in each farm were assigned based on surveys, reports, and census data in order to best replicate the existing swine population in the modeled population $[3,13]$. The accuracy statistics demonstrated the geographical locations generated for random farm placement using our model algorithm had a very high agreement with the actual observed swine farm locations and therefore, the model swine population generated is a suitable surrogate for incorporation into disease transmission models. 
Although the modeled population was a suitable representation of the actual swine farm locations in Ontario, this is not without limitations. First, the number of farms generated in the models were based on the 2011 agricultural census. Underreporting of swine farms, particularly small and backyard farms in the census could have resulted in generating fewer farms in our model. Moreover, a farm with modest number of pigs (e.g. $~ 700$ heads) could have multiple barns located in geographically dispersed location and it was unclear if the census recorded them as a single farm or counted them separately (Personal communication: Dr. Zvonimir Poljak, Department of Population Medicine, Ontario Veterinary College, University of Guelph, Guelph, ON, Canada). On the other hand, the premises registry listed almost twice the number of farm premises. This is likely because individual farm owners had the option to register multiple barns of a single "farm" separately. However, because of the restricted nature of premise registry data, we were unable to verify the proportion of farms that may have registered multiple barns. One way to overcome this issue would be to include a 'correction factor' to adjust the estimated number of farms so it better matches the number of farms derived from a different farmed animal data source(s). However, introducing a 'correction factor' would require a thorough understanding of the proportion of missing data from the primary data source, in our case the 2011 agricultural census. Since we were unable to identify a credible data source for the proportion of farms missing in the census data, we did not include a 'correction factor' with an assumption that the proportional density of the swine farms in the model would be about the same as the actual population. Second, we defined a threshold cut-off using Kappa statistics. This measure is dependent on the prevalence of an outcome [24] and could result in poor agreement when the prevalence is low. In our case, the number of $1-\mathrm{km}^{2}$ grid cells having swine farms was very low compared to the total land surface of the province ( 0.028 vs. 1$)$. A way to overcome this low-prevalence issue would be to calculate True Skill Statistics. However, the threshold defined by True Skill Statistics was extremely low (Fig. 4). Therefore, we took a conservative approach and selected the threshold cut-off where the Kappa value minimized commission error (higher specificity). Third, we did not incorporate the waterbodies that had extremely small surface areas. The reason for such consideration was because our measurement units were $1 \mathrm{~km}^{2}$ geographic blocks. Even if a unit contained a small waterbody, it would have had an adequate amount of surface areas remaining to also accommodate a swine farm (Additional file 1: Figure S4). Finally, we did not incorporate a separate geospatial data layer on soil types in the models. Although loam type soil facilitates farm waste storage, the incorporation of an agricultural ecumene data layer that included much of the land surface with supported soil types as well as easy access to local grain production for swine feeding management was considered to be a reasonable substitute.

\section{Conclusions}

In the absence of a full, identifiable population structure dataset for swine farms in Ontario, developing a model swine population that captures the key characteristics of the observed population structure while protecting producer privacy is an important methodological advancement. Such a population structure will be useful for individuals interested in modeling the spread of pathogens between farms across a landscape and using models to evaluate disease control and eradication measures.

\section{Additional file}

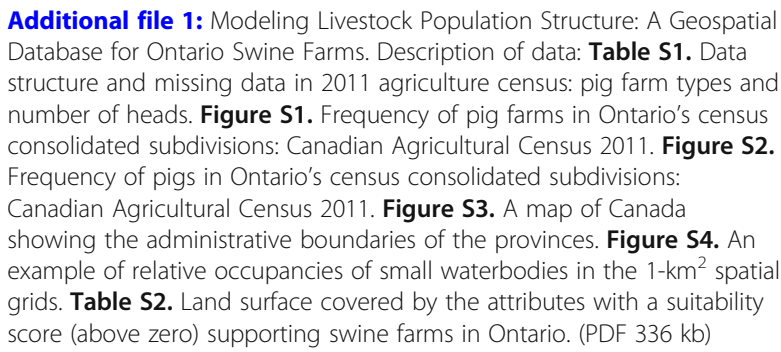

\section{Abbreviations}

AUC: Area Under the Receiver Operating Characteristics Curve; CCS: Census Consolidated Subdivisions; CIFA: Canadian Food Inspection Agency; FAD: Foreign animal diseases; GIS: Geographical Information System; OMAFRA: Ontario Ministry of Agriculture, Food and Rural Affairs; ROC: Receiver Operating Characteristics; SD: Standard deviation

\section{Acknowledgements}

We acknowledge the funding support of the Natural Sciences and Engineering Research Council (NSERC) and the Canada Research Chairs (CRC) Program. We also acknowledge data support from the Provincial Premises Registry, Ontario Ministry of Agriculture, Food and Rural Affairs, particularly Dr. Tim Pasma, Lead Veterinarian, Epidemiology, Animal Health and Welfare Branch and Alexander Heim, Coordinator, Premises Information Management for sharing the anonymized swine premises information for the model validation step and Pascale Aubry, Canadian Food Inspection Agency (CFIA) for providing information on livestock farm identification process during the event of an outbreak.

\section{Funding}

This research is funded by the Natural Sciences and Engineering Research Council (NSERC) and the Canada Research Chairs (CRC) Program.

\section{Availability of data and materials}

The Canadian Agricultural Census (2011) and the factors influencing swine farming in Ontario, Canada data were openly accessible. We have provided appropriate references to direct the reader to the source of these data. Please contact Dr. Amy Greer (agreer@uoguelph.ca) for the model pig population data.

\section{Authors' contributions}

ALG, SUK, TLS, ZP, JA conceived the study design, SUK extracted and organized the data, performed analysis, and drafted the manuscript. All co-authors reviewed the draft and consented for submission to a journal. All authors read and approved the final manuscript. 


\section{Ethics approval and consent to participate}

We received de-identified presence/absence information on swine barn locations from the Provincial Premises Registry of the Ontario Ministry of Agriculture, Food and Rural Affairs. To be specific, the database did not include any identifiable information linked to a specific farm or farmer (e.g. names, addresses and geographic locations). Because this research data did not contain identifiable information that might compromise a farmer's privacy, it did not require research ethics board (REB) approval.

\section{Consent for publication}

Not applicable

\section{Competing interests}

The authors declare that they have no competing interests

\section{Author details}

'Department of Population Medicine, Ontario Veterinary College, University of Guelph, Guelph, ON, Canada. ${ }^{2}$ Ontario Ministry of Agriculture, Food and Rural Affairs, Guelph, ON, Canada.

Received: 21 June 2017 Accepted: 24 January 2018

Published online: 30 January 2018

\section{References}

1. Brisson Y: The changing face of the Canadian hog industry: Canadian Agriculture at a Glance. Statistics Canada, Agriculture Division. Available at: http://www.statcan.gc.ca/pub/96-325-x/2014001/article/14027-eng.htm. Accessed on: 18 Oct 2016. In.; 2014

2. Whiting TL. Foreign animal disease outbreaks, the animal welfare implications for Canada: risks apparent from international experience. Can Vet J. 2003; 44(10):805-15

3. Statistics-Canada: Census of Population and Agriculture, 2011. In.; 2011.

4. Drew T. The emergence and evolution of swine viral diseases: to what extent have husbandry systems and global trade contributed to their distribution and diversity? Revue Scientifique et Technique-OIE. 2011;30(1):95.

5. Jones BA, Grace D, Kock R, Alonso S, Rushton J, Said MY, McKeever D, Mutua F, Young J, McDermott J. Zoonosis emergence linked to agricultural intensification and environmental change. Proc Natl Acad Sci. 2013;110(21):8399-404.

6. Gibbs EP. The evolution of one health: a decade of progress and challenges for the future. Vet Rec. 2014;174(4):85-91.

7. Harvey N, Reeves A, Schoenbaum MA, Zagmutt-Vergara FJ, Dube C, Hill AE, Corso BA, McNab WB, Cartwright Cl, Salman MD. The north American animal disease spread model: a simulation model to assist decision making in evaluating animal disease incursions. Prev Vet Med. 2007;82(3-4):176-97.

8. Anderson RM, RM. M: infectious diseases of humans: dynamics and control. Oxford: Oxford University Press; 1991.

9. Hethcote HW. Qualitative analyses of communicable disease models. Math Biosci. 1976;28(3):335-56

10. Sattenspiel L. Population structure and the spread of disease. Hum Biol. 1987;59(3):411-38

11. Miller JC, Volz EM. Incorporating disease and population structure into models of SIR disease in contact networks. PLoS One. 2013;8(8):e69162.

12. Census of Population, Available at: http://www.statcan.gc.ca/pub/92-195-x/ 2011001/geo/ccs-sru/ccs-sru-eng.htm, accessed on: 31 Jan 2017.

13. Ken McEwan, Marchand L: Benchmarking the Ontario Swine Industry 2011: A Report to Ontario Pork. Available at: http://www.ridgetownc.uoguelph.ca/ research/documents/mcewan_Benchmarking_Project_Final_Report.pdf. Accessed on: 6 Feb 2017. In. 2012.

14. Anonymous: Canadian Code of Practice for Environmentally Sound Hog Production. Canadian Pork Council. Available at: http://manitobapork.com/ wp-content/uploads/Canadian_Code_of_Practice_for_Environmentally_ Sound_Hog_Production.pdf. Accessed on: 8 Feb 2017. In.: 1996.

15. Lynn Marchand, McEwan K: The Impact of Township Zoning By-Laws on Ontario Swine Farms: A report to Ontario Pork. Ridgetown College, University of Guelph. Available at: http://agrienvarchive.ca/bioenergy/ download/sec1_3.pdf. Accessed on: 8 Feb 2017. In.; 1997.

16. Resources MoN: Ontario Radar DSM, Metadata record, Geographic Information Branch, Science and Information Resources Division, Ministry of Natural Resources. Available at: https://www.javacoeapp.Irc.gov.on.ca/ geonetwork/srv/en/main.home. Accessed on: 7 Feb 2017. 2012.
17. Statistics-Canada: The Lambert conformal conic map projection. Available at: http://www.statcan.gc.ca/pub/92-195-x/2011001/other-autre/mapprojprojcarte/m-c-eng.htm. Accessed on: 09 Feb 2017. 2015.

18. Generate Random Points. Available at: www.ianbroad.com. Accessed on 22 Feb 2017.

19. Stehman SV, Czaplewski RL. Design and analysis for thematic map accuracy assessment: fundamental principles. Remote Sens Environ. 1998;64(3):331-44.

20. Watson PF, Petrie A. Method agreement analysis: a review of correct methodology. Theriogenology. 2010;73(9):1167-79.

21. Fielding AH, Bell JF. A review of methods for the assessment of prediction errors in conservation presence/absence models. Environ Conserv. 1997:24(01):38-49.

22. OMAFRA: Provincial Premises Registry: Ontario Ministry of Agriculture, Food, and Rural Affairs. Available at: https://www.ontarioppr.com/home_en. html?font=M. Accessed on: 4th Mar 2017. 2012.

23. DeLong ER, DeLong DM, Clarke-Pearson DL. Comparing the areas under two or more correlated receiver operating characteristic curves: a nonparametric approach. Biometrics. 1988:837-45.

24. Allouche O, Tsoar A, Kadmon R. Assessing the accuracy of species distribution models: prevalence, kappa and the true skill statistic (TSS). J Appl Ecol. 2006; 43(6):1223-32.

25. Manel S, Williams HC, Ormerod SJ. Evaluating presence-absence models in ecology: the need to account for prevalence. J Appl Ecol. 2001;38(5):921-31.

26. Bruhn MC, Munoz B, Cajka J, Smith G, Curry RJ, Wagener DK, Wheaton WD: Synthesized population databases: A geospatial database of US poultry farms. RTI Press publication No. MR-0023-1201. Research Triangle Park, NC: RTI Press. Retrieved from https://www.rtiorg/sites/default/files/resources/ 13649076_mr-0023-1201-bruhn.pdf. Accessed on: 3rd Oct 2016. In.; 2012.

27. Rorres C, Pelletier ST, Bruhn MC, Smith G. Ongoing estimation of the epidemic parameters of a stochastic, spatial, discrete-time model for a 198384 avian influenza epidemic. Avian Dis. 2011;55(1):35-42.

28. Fabiosa JF: Assessing the impact of the exchange rate and its volatility on Canadian pork and live swine exports to the United States and Japan. 2002.

29. Statistics-Canada: Census of Population and Agriculture, 1921 and 2011. In

30. Council CP: Cull Breeding Swine Program: Annual Report For the Fiscal Year Ending March 31, 2010. Available from: http://www.cpc-ccp.com. Accessed on: 24 Oct 20162010.

31. Boklund A, Goldbach SG, Uttenthal A, Alban L. Simulating the spread of classical swine fever virus between a hypothetical wild-boar population and domestic pig herds in Denmark. Prev Vet Med. 2008:85(3-4):187-206.

32. Martínez-López B, Ivorra B, Ramos A, Sánchez-Vizcaíno JM. A novel spatial and stochastic model to evaluate the within-and between-farm transmission of classical swine fever virus. I. General concepts and description of the model. Vet Microbiol. 2011;147(3):300-9.

33. Kitching RP, Thrusfield MV, Taylor NM. Use and abuse of mathematica models: an illustration from the 2001 foot and mouth disease epidemic in the United Kingdom. Revue Scientifique et Technique-Office International des Epizooties. 2006;25(1):293.

34. Morris R, Wilesmith J, Stern M, Sanson R, Stevenson M. Predictive spatial modelling of alternative control strategies for the foot-and-mouth disease epidemic in great Britain, 2001. In: II international symposium on application of modelling as an innovative Technology in the Agri-Food Chain; MODELIT 566: 2001; 2001. p. 337-47.

\section{Submit your next manuscript to BioMed Central and we will help you at every step:}

- We accept pre-submission inquiries

- Our selector tool helps you to find the most relevant journal

- We provide round the clock customer support

- Convenient online submission

- Thorough peer review

- Inclusion in PubMed and all major indexing services

- Maximum visibility for your research

Submit your manuscript at www.biomedcentral.com/submit
) Biomed Central 